\title{
Presenting characteristics, comorbidities, and outcomes among 390 patients hospitalized with COVID-19 pneumonia in a tertiary hospital
}

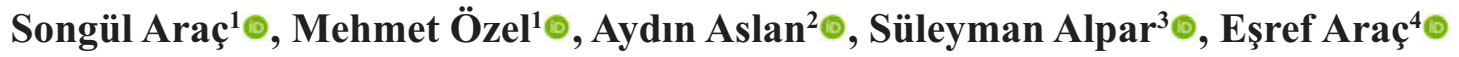 \\ ${ }^{1}$ Department of Emergency Medicine, University of Health Sciences, Diyarbakır Gazi Yaşargil Training and Research Hospital, \\ Diyarbakır, Turkey \\ ${ }^{2}$ Department of Radiology, University of Health Sciences, Diyarbakır Gazi Yaşargil Training and Research Hospital, Diyarbakır, Turkey \\ ${ }^{3}$ Department of Emergency Medicine, Diyarbakur Ergani State Hospital, Diyarbakır, Turkey \\ ${ }^{4}$ Department of Internal Medicine, University of Health Sciences, Diyarbakır Gazi Yaşargil Training and Research Hospital, Diyarbakır, \\ Turkey
}

\section{ABSTRACT}

Objectives: In this study, demographic characteristics, comorbidities, presenting symptoms, physical examination findings, laboratory findings, and administered drugs of the discharged or deceased patients admitted to our hospital and hospitalized with the COVID-19 diagnosis were compared to investigate the factors that affect mortality.

Methods: A retrospective study was performed and included COVID-19 pneumonia patients. 390 consecutive discharged or deceased patients, who were hospitalized in our hospital between March 20 and May 20, 2020, after detection of pneumonia and diagnosis of COVID-19, were included in the study.

Results: Of the 390 patients included in the study, $352(90.25 \%)$ were discharged after recovery, while 38 $(9.75 \%)$ were deceased. The average age of all the patients was $49.46 \pm 17.86$ years, the average age of the discharged patients was $47.19 \pm 16.76$ years, and the average age of the deceased patients was $70.42 \pm 13.7$ years. The average age of deceased patients was significantly higher. Of all the patients, $40.8 \%$ was PCR positive.

Conclusions: The present study revealed that the drugs that patients take due to their comorbidities have no effect on the prognosis of the disease and that the presence of comorbidity itself is indicative of the poor prognosis. Taking into account the PCR positivity of 57.9\%, even in deceased patients, we believe PCR is inadequate in the diagnosis, and $\mathrm{CT}$ is much more valuable in this regard.

Keywords: COVID-19 disease, CT images, pneumonia, reverse transcription polymerase chain reaction

$\mathrm{S}$ ince December 2019, the new Severe Acute Respiratory Syndrome Coronavirus 2 (SARS-CoV-2) outbreak has turned from a small unknown atypical pneumonia cluster into a global pandemic. Coronavirus disease 2019 (COVID-19) now affects over 200 countries with more than 11669259 confirmed cases and nearly 539906 deaths worldwide [1]. SARS-CoV2 has similar features to Severe Acute Respiratory Syndrome (SARS-CoV) and Middle East Respiratory Syndrome (MERS) coronavirus, and enters the cells through Angiotensin-Converting Enzyme 2 (ACE2) receptor, as the main entry point to infect cells $[2,3]$. 
Its mortality rate varies according to age and the presence of a chronic disease. While the mortality rate is $0.2 \%$ in healthy young adults, this rate is $>10 \%$ in the elderly with chronic diseases [4]. Limited information has been available to describe the presenting characteristics and outcomes of COVID-19 patients requiring hospitalization in Turkey. In a retrospective cohort study from China, hospitalized patients were predominantly men with a median age of 56 years; $26 \%$ required intensive care unit (ICU) care, and there was a $28 \%$ mortality rate [5]. Italy is among the most severely affected countries, with 242.173 confirmed cases, 34.026 deaths, and an observed lethality rate of $14.1 \%$, according to the most recent estimates of July 9th, 2020 [6]. Turkey has reported total of 209.962 confirmed cases along with 5300 deaths due to COVID-19 until July 9th, 2020 [7]. Although it is not yet possible to say anything about the differences between mortality rates, there are differences between demographic characteristics and comorbidity prevalences[8]. Research on the potentially modifiable risk factors related to the increased susceptibility to infection or worse outcomes among those infected, focuses on cardiovascular comorbidity, cerebrovascular diseases, hypertension, and diabetes [8,9].

In this study, demographic characteristics, comorbidities, presenting symptoms, physical examination findings, laboratory findings, and administered drugs of the discharged or deceased patients admitted to our hospital and hospitalized with the COVID-19 diagnosis were compared to investigate the factors that affect mortality.

\section{METHODS}

Following the approval of the ethics committee of our hospital for this retrospective research, 390 consecutive discharged or deceased patients, who hospitalized in our hospital between March 20 and May 20, 2020, after detection of pneumonia and diagnosis of COVID-19, were included in the study. Patients whose hospitalization continued, patients under the age of 18, patients with CT findings incompatible with COVID19 pneumonia, and patients whose data were not available were excluded from the study.

All the patients had specific symptoms of COVID19 infection, specific signs of viral pneumonia were present in computerized thoracic tomography (CT) in addition to laboratory findings. Infection in 159 patients was confirmed using reverse transcription polymerase chain reaction (RT-PCR). Two hundred thirty-one patients with negative RT-PCR results were diagnosed with COVID-19 by clinical, laboratory and imaging findings in accordance with Ministry of Health COVID-19 guidelines. In line with our hospital protocol, all COVID-19 patients underwent a detailed history, electrocardiography, standard biochemical and hematological tests after their admission to the emergency room. Patients included in the study were treated in accordance with the COVID-19 guidelines of the Ministry of Health. The patients were divided into two groups: those who were recovered and discharged and those who were deceased.

Clinical data of all patients, including gender, age, risk factors (coronary artery disease, chronic obstructive pulmonary disease, etc.) drugs used were collected through the hospital information management system and Social Security Institution Medulla system.

The institutional ethics board of the Gazi Yasargil Training and Research Hospital, an affiliate of the University of Health Science, reviewed and approved this retrospective study.

\section{Statistical Analysis}

The SPSS Version 22.0 (IBM Corp. Released 2013. IBM SPSS Statistics for Windows, Version 22.0. Armonk, NY: IBM Corp.) was used for statistical analysis. The normality of data was tested by using the Kolmogorov Smirnov test, continuous variables were compared with the Mann Whitney U test, and categorical variables were compared using the chi-square test. A $p$ - value of $<0.05$ was considered significant.

\section{RESULTS}

Of the 390 patients included in the study, 352 $(90.25 \%)$ were discharged after recovery, while 38 $(9.75 \%)$ were deceased. The average age of all the patients was $49.46 \pm 17.86$ years, the average age of the discharged patients was $47.19 \pm 16.76$ years, and the average age of the deceased patients was $70.42 \pm 13.7$ years. The average age of the deceased patients was significantly higher $(p<0.001)$. Of all the patients, 
Table 1. Clinical findings of patients with COVID-19 pneumonia

\begin{tabular}{|c|c|c|c|c|}
\hline & $\begin{array}{l}\text { All patients } \\
(\mathrm{n}=390)\end{array}$ & $\begin{array}{c}\text { Discharged } \\
(n=352)\end{array}$ & $\begin{array}{c}\text { Exitus } \\
(n=38)\end{array}$ & $p$ value \\
\hline Age (years) & $49.46 \pm 17.86$ & $47.19 \pm 16.76$ & $70.42 \pm 13.7$ & $<0.001$ \\
\hline \multicolumn{5}{|l|}{ Sex } \\
\hline Female & $188(48.2)$ & $171(48.6)$ & $17(44.7)$ & 0.652 \\
\hline Male & $202(51.8)$ & $181(51.4)$ & $21(55.3)$ & \\
\hline \multicolumn{5}{|l|}{ PCR result, $\mathrm{n}(\%)$} \\
\hline Negative & $231(59.2)$ & $215(61.1)$ & $16(42.1)$ & 0.024 \\
\hline Positive & $159(40.8)$ & $137(38.9)$ & $22(57.9)$ & \\
\hline First symptom onset to admission, days & $5.32 \pm 2.81$ & $5.33 \pm 2.89$ & $5.18 \pm 1.93$ & 0.733 \\
\hline \multicolumn{5}{|l|}{ Symptoms, n (\%) } \\
\hline Fever & $149(38.2)$ & $133(37.8)$ & $16(42.1)$ & 0.602 \\
\hline Cough & $203(52.1)$ & $183(52.0)$ & $20(52.6)$ & 0.94 \\
\hline Dispne & $88(22.6)$ & $700(19.9)$ & $18(47.4)$ & $<0.001$ \\
\hline Sputum & $9(2.3)$ & $8(2.3)$ & $1(2.6)$ & 0.88 \\
\hline Sore throat & $40(10.3)$ & $34(9.7)$ & $6(15.8)$ & 0.23 \\
\hline Myalgia & $47(12.1)$ & $41(11.6)$ & $6(15.8)$ & 0.45 \\
\hline Chest distress & $13(3.3)$ & $11(3.1)$ & $2(5.3)$ & 0.48 \\
\hline Smell and taste disorders & $8(2.1)$ & $8(2.3)$ & 0 & 0.34 \\
\hline Diarrhea & $12(3.1)$ & $10(2.8)$ & $2(5.3)$ & 0.41 \\
\hline Headache & $20(5.1)$ & $19(5.4)$ & $1(2.6)$ & 0.46 \\
\hline Nausea, vomiting & $19(4.9)$ & $19(5.4)$ & 0 & 0.14 \\
\hline Fatigue & $117(30.0)$ & $107(30.4)$ & $10(26.3)$ & 0.6 \\
\hline Systolic blood pressure & $116.53 \pm 13.26$ & $116.12 \pm 12.8$ & $120.32 \pm 16.69$ & 0.560 \\
\hline Diastolic blood pressure & $72.1 \pm 8.43$ & $72.08 \pm 8.26$ & $72.24 \pm 10$ & 0.41 \\
\hline Temperature $\left({ }^{\circ} \mathrm{C}\right)$ & $37.1 \pm 0.61$ & $37.11 \pm 0.61$ & $37.09 \pm 0.68$ & 0.58 \\
\hline Pulse rate & $84.22 \pm 12.64$ & $84.25 \pm 12.49$ & $83.97 \pm 14.15$ & 0.47 \\
\hline Oxygen saturation & $96,17 \pm 4.15$ & $96.84 \pm 3.49$ & $90.03 \pm 4.78$ & $<0.001$ \\
\hline Underlying comorbidities, $\mathrm{n}(\%)$ & $153(39.2)$ & $122(347)$ & $31(81.6)$ & $<0.001$ \\
\hline Hypertension & $82(21.0)$ & $59(16.8)$ & $23(60.5)$ & $<0.001$ \\
\hline Diabetes & $59(15.2)$ & $47(13.4)$ & $12(31.6)$ & 0.003 \\
\hline Chronic obstructive pulmonary disease & $42(10.8)$ & $34(9.7)$ & $8(21.1)$ & 0.032 \\
\hline Chronic Heart Disease & $39(10.0)$ & $33(9.4)$ & $6(15.8)$ & 0.211 \\
\hline Malignancy & $6(1.5)$ & $5(1.4)$ & $1(2.6)$ & 0.56 \\
\hline Chronic Kidney Disease & $12(3.1)$ & $11(3.1)$ & $1(2.6)$ & 0.86 \\
\hline Cerebrovascular diseases & $9(2.3)$ & $6(1.7)$ & $3(7.9)$ & 0.016 \\
\hline Dementia & $4(10)$ & $2(0.6)$ & $2(5.3)$ & 0.006 \\
\hline \multicolumn{5}{|c|}{ Medications Used by COVID-19 Patients Before Admission, $\mathrm{n}(\%)$} \\
\hline Antithrombotic & $61(15.6)$ & $43(12.2)$ & $18(47.4)$ & $<0.001$ \\
\hline Diuretic & $31(7.9)$ & $22(6.3)$ & $9(23.7)$ & $<0.001$ \\
\hline Beta blocker & $44(11.3)$ & $35(9.9)$ & $9(23.7)$ & 0.011 \\
\hline Calcium channel blockers & $48(12.3)$ & $34(9.7)$ & $14(36.8)$ & $<0.001$ \\
\hline ACE inhibitor & $25(6.4)$ & $21(6.0)$ & $4(10.5)$ & 0.27 \\
\hline Angiotensin receptor blocker & $34(8.7)$ & $22(6.3)$ & $12(31.6)$ & $<0.001$ \\
\hline Oral antidiabetic & $43(11.1)$ & $35(9.9)$ & $8(21.6)$ & 0.031 \\
\hline Insulin & $20(5.1)$ & $13(3.7)$ & $7(18.4)$ & $<0.001$ \\
\hline Inhaled drugs & $40(10.3)$ & $32(9.1)$ & $8(21.1)$ & 0.021 \\
\hline Stay at hospital (days) & $10.18 \pm 8.02$ & $9.65 \pm 5.87$ & $15.08 \pm 17.94$ & 0.224 \\
\hline
\end{tabular}

Data are shown as mean \pm standard deviation or $n(\%)$ 
Table 2. Laboratory findings of patients with COVID-19 pneumonia

\begin{tabular}{lcccc}
\hline & $\begin{array}{c}\text { All patients } \\
(\mathbf{n}=\mathbf{3 9 0})\end{array}$ & $\begin{array}{c}\text { Discharged } \\
(\mathbf{n}=\mathbf{3 5 2})\end{array}$ & $\begin{array}{c}\text { Exitus } \\
(\mathbf{n}=\mathbf{3 8})\end{array}$ & $\boldsymbol{p}$ value \\
\hline WBC $\left(10^{9} / \mathrm{L}\right)$ & $8.1 \pm 5.59$ & $7.63 \pm 4.22$ & $12.5 \pm 11.73$ & $\mathbf{0 . 0 0 1}$ \\
\hline Neutrophil $\left(10^{9} / \mathrm{L}\right)$ & $5.77 \pm 4.46$ & $5.54 \pm 4$ & $7.86 \pm 7.21$ & 0.46 \\
\hline Lymphocyte $\left(10^{9} / \mathrm{L}\right)$ & $1.78 \pm 2.47$ & $1.67 \pm 0.76$ & $2.8 \pm 7.57$ & $<\mathbf{0 . 0 0 1}$ \\
\hline Platelets $\left(10^{9} / \mathrm{L}\right)$ & $232.92 \pm 83.52$ & $232.84 \pm 79.92$ & $233.66 \pm 112.9$ & 0.638 \\
\hline Hb $(\mathrm{g} / \mathrm{dL})$ & $13.49 \pm 2.05$ & $13.59 \pm 1.95$ & $12.61 \pm 2.69$ & $\mathbf{0 . 0 1 1}$ \\
Htc $(\%)$ & $41.74 \pm 5.67$ & $42.1 \pm 5.04$ & $38.43 \pm 9.23$ & $\mathbf{0 . 0 0 3}$ \\
\hline Albumin $(\mathrm{g} / \mathrm{L})$ & $42.43 \pm 5.62$ & $43.36 \pm 4.48$ & $33.79 \pm 7.58$ & $<\mathbf{0 . 0 0 1}$ \\
\hline ALT $(\mathrm{U} / \mathrm{L})$ & $28.88 \pm 32.05$ & $28.32 \pm 26.42$ & $34.08 \pm 64.39$ & 0.69 \\
\hline AST $(\mathrm{U} / \mathrm{L})$ & $31.28 \pm 34.61$ & $29.39 \pm 26.34$ & $48.76 \pm 75.25$ & $\mathbf{0 . 0 0 2}$ \\
\hline CRP $(\mathrm{mg} / \mathrm{L})$ & $51.33 \pm 68.44$ & $40.95 \pm 58.55$ & $147.51 \pm 78.7$ & $<\mathbf{0 . 0 0 1}$ \\
Ca $(\mathrm{mg} / \mathrm{dL})$ & $8.58 \pm 0.5$ & $8.63 \pm 0.46$ & $8.1 \pm 0.56$ & $<\mathbf{0 . 0 0 1}$ \\
\hline Cl $(\mathrm{mmol} / \mathrm{L})$ & $103.48 \pm 4.2$ & $103.34 \pm 3.29$ & $104.84 \pm 8.95$ & 0.905 \\
\hline Creatinin $(\mathrm{mg} / \mathrm{dL})$ & $0.96 \pm 0.78$ & $0.91 \pm 0,76$ & $1.4 \pm 0.84$ & $<\mathbf{0 . 0 0 1}$ \\
\hline LDH $(\mathrm{U} / \mathrm{L})$ & $280.75 \pm 129.05$ & $267.69 \pm 116.95$ & $401.68 \pm 169.41$ & $<\mathbf{0 . 0 0 1}$ \\
\hline K $(\mathrm{mmol} / \mathrm{L})$ & $4.11 \pm 0.51$ & $4.09 \pm 0.49$ & $4.28 \pm 0.66$ & 0.167 \\
\hline Na $(\mathrm{mEq} / \mathrm{L})$ & $137.16 \pm 3.53$ & $137.16 \pm 2.74$ & $137.08 \pm 7.71$ & 0.02 \\
\hline Urea $(\mathrm{mg} / \mathrm{dL})$ & $33.33 \pm 28.03$ & $29.25 \pm 20.02$ & $71.11 \pm 53.27$ & $<\mathbf{0 . 0 0 1}$ \\
\hline D-dimer $(\mathrm{ng} / \mathrm{mL})$ & $395,05 \pm 553,88$ & $342,24 \pm 480,2$ & $884,21 \pm 875,02$ & $<\mathbf{0 . 0 0 1}$ \\
\hline Troponin $(\mathrm{ng} / \mathrm{mL})$ & $0.14 \pm 0.39$ & $0.13 \pm 0.35$ & $0.25 \pm 0.66$ & $<\mathbf{0 . 0 0 1}$ \\
\hline Da & & & \\
\hline
\end{tabular}

Data are shown as mean \pm standard deviation or $\mathrm{n}(\%)$

$40.8 \%$ was PCR positive. PCR positivity was significantly higher by $57.9 \%$ in deceased patients $(p=$ $0.024)$. There were no gender differences between the two groups and in all patients (Table 1).

The duration between symptom onset and hospitalization was $5.32 \pm 2.81$ days in all patients included in the study. The most common symptoms were cough by $52.1 \%$, fever by $38.2 \%$, and fatigue by $30 \%$, respectively. In the comparison of the symptoms of the patient groups, there was no significant difference be- tween symptoms other than dyspnea, and the incidence of dyspnea was found to be higher in deceased patients $(47.4 \%)$ than in the discharged patients $(19.9 \%)(p<0.001)$.

According to the results of the physical examination between the groups, the mean saturation in deceased patients was $90 \%$, and $96 \%$ in the discharged patients. The mean saturation was significantly lower in the deceased group $(p<0.001)$.

The presence of comorbidity was significantly

Tablo 3. CT features of patients with COVID-19 pneumonia

\begin{tabular}{lcccc}
\hline & Total & Discharged & Exitus & $\boldsymbol{p}$ value \\
\hline Ventral and dorsal & $62(15.9)$ & $41(11.6)$ & $21(55.3)$ & $<\mathbf{0 . 0 0 1}$ \\
Bilateral & $291(74.6)$ & $254(72.2)$ & $37(97.4)$ & $\mathbf{0 . 0 0 1}$ \\
Perihilar & $89(22.8)$ & $72(20.5)$ & $17(44.7)$ & $\mathbf{0 . 0 0 1}$ \\
Peripheral & $359(92.1)$ & $325(92.3)$ & $34(89.5)$ & 0.536 \\
\hline
\end{tabular}

Data are shown as $\mathrm{n}(\%)$ 
higher in the deceased group ( $p<0.001)$.). The most common additional disease in the deceased group was hypertension by $60 \%$. HT, DM, cerebrovascular disease and dementia were significantly higher in the deceased group $(p<0.001, p=0.003, p=0.016$ and $p=$ 0.006 , respectively) (Table 1 ).

Considering the drug use in the deceased group, antithrombotic, diuretic, beta blocker, ARB, calcium channel blocker, oral antidiabetic and insulin use was significantly higher $(p<0.001, p<0.001, p=0.011$, $p<0.001, p<0.001, p=0.031$ and $p<0.001$, respectively), whereas there was no statistical difference in the use of ACE inhibitors compared to the discharged patients $(p=0.27)$.

In the examination of the laboratory findings of the patient groups, hemogram parameters leukocyte and lymphocyte counts were significantly higher in the deceased patients ( $p=0.001$ and $p<0.001$, respectively), while hemoglobin and hematocrit levels were significantly lower ( $p=0.011, p=0.003$, respectively) (Table 2).
Of the biochemical parameters, albumin was significantly lower, while CRP, LDH, urea, creatine, Ddimer and troponin were significantly higher $(p<$ 0.001 ).

In the evaluation of lung involvement in thoracic CT, perihilar involvement, ventral and dorsal involvement, and bilateral lung involvement were significantly higher in the deceased patients $(p<0.001)$ (Tablo 3) (Fig. 1).

\section{DISCUSSION}

In the study, advanced age and comorbid factors such as hypertension and diabetes were found to be significantly higher in deceased patients in line with the literature. In deceased patients, the most common comorbidity was hypertension by $60 \%$, in line with the literature $[8,10]$. Although preliminary studies reported higher COVID-19 incidence in the male gender, subsequent studies found no difference between



Fig.1. CT scan of 53-year old female with COVID-19. Bilateral ventral and dorsal located ground glass opacities. 
the genders as in the present study $[11,12]$. We believe, the higher infection incidence in the male gender in the preliminary research was due to the fact that most of affected patients associated with the seafood wholesale market were male workers.

The most common presenting symptoms of the patients were cough by $52.1 \%$, fever by $38.2 \%$, and fatigue by $30 \%$, respectively, in line with the literature $[8,13]$. As expected, dyspnea incidence was higher in the deceased group, and thus saturations were lower. Some studies have reported that ACE/ARB use increases mortality [3, 14-16]. However, many studies and meta-analysis studies have shown no such risk [17-19], and major cardiology scientific associations, including the ACC, HFSA, AHA, and ESC Hypertension Council, have rejected these correlation hypotheses [20]. The significantly higher use of antithrombotics, diuretics, beta blockers, ARBs, calcium channel blockers, oral antidiabetics and insulin in the deceased group in the study is believed to be due to the presence of hypertension and diabetes, not the drugs used. Although the use of all antihypertensives was significantly higher in the deceased group compared to the discharged group, it is important to note that the use of ACE inhibitors did not differ between the groups, indicating that the use of ACE inhibitors does not increase the risk of mortality.

In the laboratory findings, the infection indicators CRP, leukocyte and albumin (as negative acute phase reactants) were significantly different between the two groups as expected. (Table 2). In the deceased group, CRP, LDH, urea, creatine, D-dimer, troponin, leukocyte and lymphocyte levels were significantly higher, while albumin, hemoglobin, and hematocrit levels were significantly lower. Many studies have shown similar results to our findings, but despite the fact that lymphopenia was observed in COVID-19 patients with particularly poor prognosis and in many patients in our study, the mean lymphocyte levels in both groups were within the normal limits, but the lymphocyte count in deceased patients was found to be significantly higher compared to discharged patients [10-12].

Laboratory values suggest that COVID-19 infection may be associated with cellular immunodeficiency, coagulation activation, myocardial damage, hepatic damage, and kidney damage. We believe that the cause of mortality in COVID-19 pneumonia is hy- poxia and shock caused by the direct effect of the virus, and the cytokine storm that develops due to inflammatory response.

In the evaluation of lung involvement in thoracic $\mathrm{CT}$, perihilar involvement, ventral and dorsal involvement, and bilateral lung involvement were significantly higher in the deceased patients. In the literature review, it was found that there are findings indicating that bilateral lung involvement increases mortality, similar to the results of this study [21]. However, there was no study of perihilar involvement in particular.

\section{CONCLUSION}

The present study suggests that advanced age, presence of comorbidity, the levels of laboratory parameters such as CRP, creatine, D-dimer, troponin, hemoglobin and albumin, and bilateral and perihilar involvement in CT can be considered as a sign of poor prognosis in COVID-19 patients. The present study revealed that the presence of comorbidity itself is indicative of the poor prognosis. More comprehensive and detailed studies are needed to determine the death effect of drug use. Taking into account the PCR positivity of $57.9 \%$, even in deceased patients, we believe PCR is inadequate in the diagnosis, and CT is much more valuable in this regard.

\section{Authors' Contribution}

Study Conception: EA, SA, MÖ, SA, AA; Study Design: EA, SA, MÖ, SA, AA; Supervision: EA, SA, MÖ, SA, AA; Funding: EA, SA, MÖ, SA, AA; Materials: EA, SA, MÖ, SA, AA; Data Collection and/or Processing: EA, SA, MÖ, SA, AA; Statistical Analysis and/or Data Interpretation: EA, SA, MÖ, SA, AA; Literature Review: EA, SA, MÖ, SA, AA; Manuscript Preparation: EA, SA, MÖ, SA, AA and Critical Review: EA, SA, MÖ, SA, AA.

\section{Conflict of interest}

The authors disclosed no conflict of interest during the preparation or publication of this manuscript.

\section{Financing}

The authors disclosed that they did not receive any grant during the conduction or writing of this study. 


\section{REFERENCES}

1. World Health Organization. Coronavirus Disease (COVID-19) Situation Report - 170 . Available from: https:/www.who.int/docs/default-source/coronaviruse/situationreports/20200708-covid-19-sitrep-170.pdf?sfvrsn=bca86036_2. Accessed in 2020 (Aug 28).

2. Liu J, Zheng X, Tong Q, Li W, Wang B, Sutter K, et al. Overlapping and discrete aspects of the pathology and pathogenesis of the emerging human pathogenic coronaviruses SARS-CoV, MERS-CoV, and 2019-nCoV. J Med Virol 2020;92:491-4.

3. Selçuk M, Çınar T, Keskin M, Çiçek V, Kılıç Ş, Kenan B, et al. Is the use of ACE inb/ARBs associated with higher in-hospital mortality in Covid-19 pneumonia patients? Clin Exp Hypertens 2020;42:738-42.

4. Bravi F, Flacco ME, Carradori T, Volta CA, Cosenza G, De Togni A, et al. Predictors of severe or lethal COVID-19, including angiotensin converting enzyme inhibitors and angiotensin II receptor blockers, in a sample of infected Italian citizens. PLoS One 2020;15:e0235248.

5. Zhou F, Yu T, Du R, Fan G, Liu Y, Liu Z, et al. Clinical course and risk factors for mortality of adult inpatients with COVID-19 in Wuhan, China: a retrospective cohort study. Lancet 2020;395:1054-62.

6. Istituto Superiore di Sanità. Dati della Sorveglianza integrata COVID-19 in Italia [COVID-19 integrated surveillance data in Italy]. Available from: https://www.epicentro.iss.it/coronavirus/sars-cov-2-dashboard. Accessed in 2020 (Aug 28).

7. T.C Sağlık Bakanlığı Korona Tablosu. Available from: https://covid19.saglik.gov.tr/. Accessed in 2020 (Aug 28).

8. Richardson S, Hirsch JS, Narasimhan M, Crawford JM, McGinn T, Davidson KW, et al. Presenting characteristics, comorbidities, and outcomes among 5700 patients hospitalized with COVID-19 in the New York City Area. JAMA 2020;323:20529.

9. Guan WJ, Ni ZY, Hu Y, Liang W, Ou C, He J, et al. Clinical characteristics of coronavirus disease 2019 in China. N Engl J Med 2020;382:1708-20.

10. Fang L, Karakiulakis G, Roth M. Are patients with hypertension and diabetes mellitus at increased risk for COVID-19 infection? Lancet Respir Med 2020;8:e21.

11. Chen N, Zhou M, Dong X, Qu J, Gong F, Han Y, et al. Epidemiological and clinical characteristics of 99 cases of 2019 novel coronavirus pneumonia in Wuhan, China: a descriptive study. Lancet 2020;395:507-13.

12. Liu Y, Du X, Chen J, Jin Y, Peng L, Wang HHX, et al. Neutrophil-to-lymphocyte ratio as an independent risk factor for mortality in hospitalized patients with COVID-19. J Infect 2020;81:e6-e12.

13. Liabeuf S, Moragny J, Bennis Y, Batteux B, Brochot E, Schmit JL, et al. Association between renin-angiotensin system inhibitors and COVID-19 complications. Eur Heart J Cardiovasc Pharmacother 2020 Jun 12;pvaa062. doi: 10.1093/ehjcvp/pvaa062.

14. Sommerstein R, Kochen MM, Messerli FH, Gräni C. Coronavirus disease 2019 (COVID-19): do angiotensin-converting enzyme inhibitors/angiotensin receptor blockers have a biphasic effect? J Am Heart Assoc 2020;9:e016509.

15. Rico-Mesa JS, White A, Anderson AS. Outcomes in patients with COVID-19 infection taking ACEI/ARB. Curr Cardiol Rep 2020;22:1-4.

16. Mehra MR, Desai SS, Kuy S, Henry TD, Patel AN. Cardiovascular disease, drug therapy, and mortality in Covid-19. N Engl J Med 2020;382:e102.

17. Pranata R, Permana H, Huang I, Lim MA, Soetedjo NNM, Supriyadi R, et al. The use of renin angiotensin system inhibitor on mortality in patients with coronavirus disease 2019 (COVID19): a systematic review and meta-analysis. Diabetes Metab Syndr 2020;14:983-90.

18. Patients taking ACE-i and ARBs who contract COVID-19 should continue treatment, unless otherwise advised by their physician. American Heart Association. Available from: https://newsroom.heart.org/news/patients-taking-ace-i-and-arbswho-contract-covid-19-should-continue-treatment-unless-otherwise-advised-by-their-physician. Accessed in 2020 (Aug 28). 19. Mahdjoub E, Mohammad W, Lefevre T, Debray MP, Khalil A. Admission chest CT score predicts 5-day outcome in patients with COVID-19. Intensive Care Med 2020;46:1648-50.

20. Yuan M, Yin W, Tao Z, Tan W, Hu Y. Association of radiologic findings with mortality of patients infected with 2019 novel coronavirus in Wuhan, China. PLoS One 2020;15:1-10.

21. Hu L, Chen S, Fu Y, Gao Z, Long H, Ren HW, et al. Risk factors associated with clinical outcomes in 323 COVID-19 hospitalized patients in Wuhan, China. Clin Infect Dis 2020;71:2089-98. 